\title{
Reply to Schoeller et al. ${ }^{1,2}$
}

\section{Dear Editor:}

We thank Schoeller et al. for their interest in our recent report on energy intake trends in U.S. children (1) and for their comments that aim to heighten awareness of the challenges involved in using self-report to estimate dietary intake. Self-report is currently the only method practical for use in large-scale studies designed to monitor intake trends. However, as noted throughout the article, although dietary self-report measures are subject to reporting error and bias, self-reported energy intake (SREI) is thought to be especially susceptible. This motivated our use of several strategies that aimed to either reduce or evaluate the potential impact of misreporting on intake trends. The use of these strategies yielded trends in energy intake that were, in fact, plausible and consistent with trends in child obesity.

One strategy involved ensuring that energy intake trends were similar before and after filtering out implausible SREI data by applying a method developed by Huang et al. (2), an approach critiqued by Schoeller et al. Contrary to assertions made by Schoeller et al., the work by Huang et al. supports the utility of sensitivity analyses using this approach to exclude implausible SREI in both descriptive and cross-sectional analyses (2). They showed, for example, that excluding implausible SREI increased rather than decreased mean SREI in adults $(9.6 \mathrm{MJ} / \mathrm{d}$ after exclusions vs. $8.3 \mathrm{MJ} / \mathrm{d}$ in the full sample) and strengthened the association between BMI and SREI (coefficient \pm SE $=0.69 \pm 0.04$ after exclusions vs. $0.05 \pm 0.02$ or virtually null in the full sample). Filtering out implausible SREI also strengthened associations between BMI and other postulated obesogenic dietary factors such as snacking frequency. It also eliminated the disparity in the slope of the relation between body weight and SREI vs. estimated energy needs, which are theoretically equivalent; the disparity in these slopes was large and suggestive of biased SREI reporting in the full sample. Consistent with doubly labeled water studies that document a greater tendency to underreport energy intake at older ages but to overreport in young children (3), we found in NHANES that excluding implausible SREI increased median energy intakes in older children but reduced intake estimates in adolescents. More importantly, the consistency of results obtained after excluding less plausible SREI data suggests that misreporting is unlikely to have meaningfully influenced intake trends.

The prevalence of SREI misreporting often varies across population subgroups characterized by factors such as race (2). Consequently, it was even more critical to confirm, as we did, that race/ethnic disparities in energy intake trends were not affected by excluding the varied proportion of each subgroup with implausible SREI data.

Despite assertions to the contrary, the energy intake trends we reported are, in fact, highly consistent with the changes in child obesity (BMI $>95$ th age- and sex-specific percentile) observed in NHANES (4). The small net decline in the prevalence of obesity in 2003-2004, 2007-2008, and 2009-10 among children aged 2-5 y $(13.9 \%, 10.1 \%$, and $12.1 \%$, respectively) was accompanied by a similar small decline in median SREI (e.g., 1533, 1375, and $1401 \mathrm{kcal} / \mathrm{d}$ in girls; net change of $-132 \mathrm{kcal}$ ). In adolescents, there was an apparent plateau in the rate of increase in obesity over the same survey cycles $(17.4 \%, 18.1 \%$, and $18.4 \%)$, which was also accompanied by a small reduction in median SREI (e.g., 2027, 1838, and $1935 \mathrm{kcal}$ in girls; -92 kcal). Based on validated models of the energy intake-body weight relation in children developed by Hall et al. (5), cited by Schoeller et al., an excess intake of $\sim 29 \mathrm{kcal} / \mathrm{d}$ would promote a $1-\mathrm{kg}$ weight gain in girls aged 15 y before a new weight equilibrium would be reached. Thus, a mean decline on the order of $92 \mathrm{kcal}$ could potentially lead to a small decline in mean weight - of $\sim 3.2 \mathrm{~kg}$ - in girls of this age. Over time, sustained reductions of 100-200 kcal/ $\mathrm{d}$ could lead to modest reductions in mean weight on the order of $2-4 \mathrm{~kg}$ at age $7 \mathrm{y}$, and $4-9 \mathrm{~kg}$ at age $18 \mathrm{y}$. However, as noted by Hall et al. (5), much larger sustained changes in intake-on the order of $\geq 400 \mathrm{kcal} / \mathrm{d}$ - would be needed to promote notable shifts in the development of obesity. Moreover, subsequent shifts in obesity prevalence estimated in NHANES in 2011-2012a moderate decline to $8.4 \%$ for children aged $2-5$ y but a small increase to $20.5 \%$ in adolescents (5) - are consistent with both the plateau in energy intake we observed in young children and with the contrasting upturn in intake among teens in 2009-2010. Given the modest changes in estimated energy intake, the fact that shifts in obesity prevalence were largely nonsignificant, and the problems inherent in making inferences based on ecologic comparisons, we chose not to emphasize comparisons of these trends in the article.

In addition to sensitivity analyses excluding implausible SREI, a second strategy to address concerns regarding potential error and bias was to limit our analysis of trends to surveys using the multiple-pass method to collect dietary recalls (6). We also avoided relying exclusively on a single recall to characterize usual intake by applying methods that enabled us to incorporate a second recall when available, as well as to account for predictors of variability in intake such as weekend days (7). Together, these strategies yielded energy intake trends highly consistent with trends in obesity over the same period. Nonetheless, as Schoeller et al. acknowledge, we stated clearly throughout the article (1) that despite our best efforts, it was not possible to truly ascertain the extent to which error or bias may have influenced energy intake trends. Given the importance of assessing changes in energy intake for combating the ongoing obesity epidemic, we strongly advocate the use of such strategies, as well as the continued development of methods that aim to further reduce error and bias in dietary reporting, increase the accuracy of food composition data used to quantify intake, and identify misreporters (5) and calibrate their misreported intakes (8). Substantial errors in estimated energy intake imply important errors in estimated intakes of foods and nutrients. Because doubly labeled water estimates of energy expenditure cannot be used to study food intake, it is critical to refine methods that maximize the validity of estimates of foods, nutrients, and concomitant intakes of energy to validly assess how food policies influence excess intake, and thus the obesity epidemic (9).

\section{${ }^{1}$ Supported by the Robert Wood Johnson Foundation (grant 70017), the $\mathrm{NIH}$ (R01DK098072), and the National Institute for Child Health and Development (CPC 5 R24 HD050924). \\ ${ }^{2}$ Author disclosures: MA Mendez, D Sotres-Alvarez, DR Miles, MM Slining, and BM Popkin, no conflicts of interest. \\ Michelle A Mendez Daniela Sotres-Alvarez Donna R Miles Meghan M Slining Barry M Popkin}

From the Department of Nutrition (MAM, e-mail: mmendez@ email.unc.edu; BMP), the Carolina Population Center (DRM), 
and the Department of Biostatistics (DS-A), University of North Carolina at Chapel Hill, Chapel Hill, NC; and Furman University, Greenville, SC (MMS).

\section{References}

1. Mendez MA, Sotres-Alvarez D, Miles DR, Slining MM, Popkin BM. Shifts in the recent distribution of energy intake among U.S. children aged 2-18 years reflect potential abatement of earlier declining trends. J Nutr 2014;144:1291-7.

2. Huang TT, Roberts SB, Howarth NC, McCrory MA. Effect of screening out implausible energy intake reports on relationships between diet and BMI. Obes Res 2005;13:1205-17.

3. Burrows TL, Martin RJ, Collins CE. A systematic review of the validity of dietary assessment methods in children when compared with the method of doubly labeled water. J Am Diet Assoc 2010;110:1501-10.

4. Ogden CL, Carroll MD, Kit BK, Flegal KM. Prevalence of childhood and adult obesity in the United States, 2011-2012. JAMA 2014;311:806-14.
5. Hall KD, Butte NF, Swinburn BA, Chow CC. Dynamics of childhood growth and obesity: development and validation of a quantitative mathematical model. Lancet Diabetes Endocrinol 2013;1:97-105.

6. Moshfegh AJ, Rhodes DG, Baer DJ, Murayi T, Clemens JC, Rumpler WV, Paul DR, Sebastian RS, Kuczynski KJ, Ingwersen LA, et al. The US Department of Agriculture Automated Multiple-Pass Method reduces bias in the collection of energy intakes. Am J Clin Nutr 2008;88:324-32.

7. Tooze JA, Kipnis V, Buckman DW, Carroll RJ, Freedman LS, Guenther PM, Krebs-Smith SM, Subar AF, Dodd KW. A mixed-effects model approach for estimating the distribution of usual intake of nutrients: the NCI method. Stat Med 2010;29:2857-68.

8. Freedman LS, Commins JM, Moler JE, Arab L, Baer DJ, Kipnis V, Midthune D, Moshfegh AJ, Neuhouser ML, Prentice RL, et al. Pooled results from 5 validation studies of dietary self-report instruments using recovery biomarkers for energy and protein intake. Am J Epidemiol 2014;180:172-88.

9. Hébert JR, Hurley TG, Steck SE, Miller DR, Tabung FK, Peterson KE, Kushi LH, Frongillo EA. Considering the value of dietary assessment data in informing nutrition-related health policy. Adv Nutr 2014;5(4):447-55.

doi:10.3945/jn.114.202770 